\title{
A planta redescoberta: um relato do encontro da ayahuasca com o povo Yudjá
}

[ Plant regained: an account of the ayahuasca encounter with the Yudjá people

\section{Tânia Stolze Lima ${ }^{\mathrm{I}}$}

Intervenção preparada para o encerramento da VI ReACT|EntreViver, realizada no IEB/USP de I6 a I9 de maio de 20I7. Agradeço vivamente a Joana Cabral, Stelio Marras, Renzo Taddei e a todo o pessoal da organização dessa reunião um convite que muito me honra e muito me inspirou.

\begin{abstract}
RESUMO - Oferecendo-se mais como uma fala do que um artigo, este texto é um relato etnográfico sobre um movimento de recriação do xamanismo que tem animado o povo Yudjá nos últimos cinco anos e que foi deslanchado por seu encontro com a ayahuasca. A fim de desdobrar o meu próprio encontro com esse encontro, procuro criar uma vizinhança ou afinidade entre o movimento Yudjá, o conceito deleuze-guattariano de agenciamentos e certos movimentos que animam a ecosofia guattariana e as cosmopolíticas stengersianas.

- PALAVRAS-CHAVE • Yudjá; xamanismo; ayahuasca; cosmopolítica; ameríndios. .
\end{abstract}

\begin{abstract}
More a speech than an article, this text is an ethnographic account of a movement to recreate shamanism that has animated the Yudjá people in the last five years and which was triggered by their encounter with ayahuasca. In order to unfold my own encounter with this encounter, I seek to create a proximity or affinity between the Yudjá movement, the Deleuze-guattarian concept of assemblages, and some dimensions of Félix Guattari's ecosophy and Isabelle Stengers' cosmopolitics. - KEYWORDS · Yudjá; shamanism; ayahuasca; cosmopolitics; Amerindians.
\end{abstract}

Recebido em I6 de dezembro de 2017

Aprovado em 2 de fevereiro de 2018

LIMA, Tânia Stolze. A planta redescoberta: um relato do encontro da ayahuasca com o povo Yudjá. Revista do Instituto de Estudos Brasileiros, Brasil, n. 69, p. II8-I36, abr. 2018.

DOI: http://dx.doi.org/Io.II6o6/issn.23I6-90IX.voi69pII8-I36

I Universidade Federal Fluminense (UFF, Niterói, RJ, Brasil). 
Aqui em São Paulo, durante um passeio no Sesc-Ipiranga em outubro de 2015, Mareaji (um velho amigo Yudjá) me disse que eu já não reconheceria a aldeia Tubatuba,

- Agora, o que o pessoal sonha, o pessoal faz!

E tirando da bolsa uma garrafa com alguns dedos de um líquido escuro me perguntou se eu queria tomar um pouco de ayahuasca... Isso de fato me espantou. Eu sabia desde junho daquele ano por Karin que o famoso chá do noroeste amazônico tinha finalmente chegado até o sudeste amazônico, até o alto Xingu, e foi com um grande sorriso que Karin respondeu a minha pergunta:

- Ih, na aldeia tá cheio... todo mundo plantou!

O passeio com Mareaji e sua esposa ocorreu um dia depois do Seminário Variações do Corpo Selvagem, que reuniu bem uns vinte intelectuais para uma discussão do pensamento de Eduardo Viveiros de Castro. Quem imaginaria que após dois dias tão intensos de conversação eu seria convidada a me defrontrar com um dispositivo do perspectivismo ameríndio que iria começar a mudar esse problema para mim: de uma cosmologia relacional ou uma ontologia, o perspectivismo ia começar a mostrar sua atração por um polo que chamarei de pragmática especulativa.

Minha intervenção é uma tentativa de compor um relato etnográfico a partir da preciosa experiência de recriação das conexões entre sonhar e fazer que os Yudjá generosamente compartilharam comigo quando estive morando com o pessoal da aldeia Tubatuba entre julho e outubro do ano passado (20I6).

Assim Areyaku me apresentou a ayahuasca (também chamada mariri, vegetal, medicina, remédio, chá, cipó, wapa, wapa itxa, kubepa),

- Mariri mostra "coisas" pra gente, mostra o que a gente tem, a cultura, a nossa bebida, mostra música, mostra tudo; o que a gente cuida, o mato, a terra, os peixes, e o rio também, pra assim a gente ficar tranquilo. Mostra o que a gente deixou pra trás, mostra as músicas que deixamos pra trás... A gente não pode perder a nossa cultura, a gente pode levar pra frente, a gente é novo ainda mas está levando pra 
frente. É isso que estou vendo acontecer aqui [em Tubatuba]. Pra mim é muito legal esse mariri, mostra as "coisas", pra gente "segurar" nossa terra - então é por isso que tô muito alegre com isso.

Minha experiência de campo, voltada como ela foi para a escuta do que os Yudjá tinham para me contar, me levava a uma analogia com a Renascença, por seus apaixonados investimentos na retomada do passado, suas entusiásticas recriações de vínculos com uma variedade de outros mundos, um florescimento extraordinário da arte da miçanga, um pronunciado e explícito investimento na experimentação ritual e na pesquisa onírica - sem falar na autoconfiança e no sentir-se bem consigo mesmos de dar inveja. Em todo caso, forte era o contraste no modo como os Yudjá me receberam em 2016 e em I984, em meus primeiros cinco meses de campo. Mareaji, por exemplo, me afirmava em I984 que eu tinha chegado tarde demais, pois os pajés já tinham morrido, e já tinha acabado tudo... Esse "tudo" concernindo aos festivais xamânicos de criação e celebração das relações com os espíritos não mais realizados desde os anos I970. Agora era o contrário... pois, como me disse mais de uma vez Yabaiwa,

- O passado não está no passado.

Me ocorria assim indagar,

- O que será que aconteceu para provocar essa vitalidade que estou testemunhando e me fazer sentir tanta emoção?

Isso em parte era uma variação da pergunta que tantas vezes me coloquei nos anos I980 a propósito do patente insucesso dos Yudjá em produzir novos pajés após a conquista dos povos do Alto Xingu em meados do século XX pelos irmãos Villas Boas. Mesmo nas semanas em que me dediquei a pensar essa fala, a pergunta se impôs como um sintoma irresistível, como uma certeza de que está rolando um acontecimento de grande importância para os Yudjá. No entanto, é evidentemente irrespondível a pergunta “o que aconteceu?”, ainda mais que, transportada para essa fala, ela já não é feita no registro da história, mas no do devir: "todo acontecimento é uma névoa [...], há nel[e] uma parte que sua realização não basta para realizar, um devir em si mesmo que está sempre, a um só tempo, nos esperando e nos precedendo como uma terceira pessoa do infinitivo, uma quarta pessoa do singular"2.

Assumir que o acontecimento é um certo clima é assumir que não se trata de buscar para ele uma explicação pela conjuntura atual, a qual sem dúvida é muito malsã e acirrou entre os Yudjá o estado de alerta habitual entre os povos ameríndios. Desmatamentos, incêndios, ressecamento do solo, acidentes provocados por relâmpagos, queda da produtividade das roças, escassez de peixes. Grande evasão, disse-me Tawaiku, de alto xinguanos para Canarana. Ao sul da Terra Indígena, as barragens Paranatinga I e II têm provocado uma baixa do rio tão acentuada que durante a vazante a navegação de barcos com motores de popa achava-se aproximadamente inviabilizada no alto curso do Xingu. Entre os vizinhos imediatos

2 DELEUZE, Gilles; PARNET, Claire. Diálogos. São Paulo: Escuta, I998, p. 78. 
dos Yudjá, os Kayabi, houve um processo de conversão maciça ao evangelismo, com demonização das práticas xamânicas e coisas do tipo. No médio Xingu, a Usina Belo Monte está provocando a morte do rio - o que é absolutamente ultrajante para os Yudjá, que são um povo que se sente pertencer originalmente à Volta Grande do Xingu, de onde tiveram que fugir no final do século XIX devido à exploração da borracha, e que vem acompanhando de perto a desgraça que se abateu sobre os seus parentes que ali permaneceram. Por fim, como me disse Yabaiwa, as notícias do fim do mundo, divulgadas por cientistas, potencializam os riscos de desabamento do céu.

Dito isso, o desafio para mim é como abrir o meu relato etnográfico para a vitalidade, a alegria, o desejo empenhados na vida em Tubatuba. Algo inquietante para muitos de nós aqui presentes: somos seduzidos, afetados e transformados por esses encontros antropológicos com os ameríndios, mas qual seria a relevância direta disso para a antropologia que produzimos? Para o que eu escrevi sobre os Yudjá, por exemplo? Se cresci num ambiente em que a tolerância às outras culturas era uma atitude de vanguarda, estou envelhecendo em um ambiente em que esse gênero de tolerância tem um significado pragmático que oscila entre a indiferença em face do que importa aos outros e o insulto 3 . O desafio que nos vem sendo posto desde uns 20 anos especialmente por Stengers é o de como nos comprometer com uma arte dos encontros, deslocada em relação à “definição antropológica do homem” característica da modernidade a fim de começar a aprender a pensar na presença dos índios, a falar na frente daqueles de quem estamos falando. Essa arte dos encontros tendo por eixo a questão cosmopolítica sobre as possibilidades de "coexistência possível, sem hierarquia”, de práticas distintas, em suas “invenções de não equivalência, de valores e obrigações" de que dependem suas existências4.

Como pensar na presença dos índios? Esse é o problema!

A fim de testar minha capacidade para enfrentá-lo (e lutar contra a maldição da tolerância da qual a prática etnográfica pode se tornar ao mesmo tempo o veículo e a vítima), pretendo experimentar um pouco, ao modo de uma ferramenta, o conceito de agenciamentos de Guattari e Deleuze, o qual já foi utilizado por Guattari em inspirados combates contra as ferramentas antropológicas que aprendi a praticar (como estrutura, sistema, linguagem, cultura) ${ }^{5}$. Pretendo arriscar-me a compor um relato a partir das regras de um jogo distinto dos jogos convencionais das ciências sociais, regras que se acham expressas de um modo luminoso neste trecho de Guattari:

Não mais se tem face a face um sujeito e um objeto e, em terceira posição, um meio de expressão; não mais se tem a tripartição entre o campo da realidade, o campo da representação e da representatividade e aquele da subjetividade. O que se tem é um agenciamento coletivo que é ao mesmo tempo sujeito, objeto e expressão. [...] Só um

3 STENGERS, Isabelle. Pour en finir avec la tolérance. In: . Cosmopolitiques. Tome 7. Paris: La Découverte/ Les Empêcheurs de penser en rond, I997.

4 Ibidem, p. 74.

5 Ver: GUATTARI, Félix. Falação em torno de velhas estruturas e novos sistemas. In: Revolução molecular: pulsações políticas do desejo. São Paulo: Brasiliense, I987, p. I57-I64. 
grupo sujeito pode trabalhar os fluxos semióticos, quebrar as significações, abrir a linguagem para outros desejos e forjar outras realidades! ${ }^{6}$.

Não é, como se pode vislumbrar, um conceito útil para se pensar lógicas culturais, transformações estruturais, mas processualidades ontológicas, criacionismo axiológico, pragmáticas especulativas - em suma, "caosmopolítica". A importante novidade do conceito de agenciamentos que cabe destacar aqui reside no modo como ele articula o problema dos nexos entre a linguagem, o mundo, a subjetividade e a política. São nexos que divergem não só do popular dualismo do mundo e da representação quanto da relação semiológica baseada no par significante-significado. $\mathrm{O}$ agenciamento desdobra-se em agenciamento maquínico e agenciamento coletivo de enunciação, e as relações que articulam essas suas duas faces heterogêneas não são relações de causalidade, de representação, de significação nem de interdependência, mas ao mesmo tempo essas faces são ditas inseparáveis, estritamente complementares. São definidas como pressuposição recíproca e excluem o primado, a hierarquia, e esquemas do tipo forma e conteúdo. É nesse sentido que divergem profundamente das relações que regem definições antropológicas do homem. Um terceiro e último componente do agenciamento, correspondente ao que o anima, é dito ser o seu eixo de forças, e concerne, em um polo, aos seus segmentos e processos de reterritorialização e, no outro, às suas pontas de desterrritorialização ${ }^{8}$.

\section{Os Yudjá ENCONTRAM a AYAHUASCA}

Meu relato versa, pois, sobre a recriação das conexões entre sonhar e fazer, sobre a composição de um novo agenciamento político-xamânico, mas só posso restituir aqui alguns de seus muito variados aspectos (dos quais não é minha intenção oferecer uma síntese).

Foi por intermédio do Centro Espírita Beneficente União do Vegetal (UDV) que a ayahuasca chegou aos Yudjá, a partir aproximadamente de 20I2. A fama do cipó já era contudo conhecida desde alguns anos porque Mahum tinha experimentado entre os Ashaninca e os Kaxinawa no Acre por volta de 2005. De acordo com Tawaiku, foi por

6 Idem. Micropolítica do fascismo. In: . Revolução molecular: pulsações políticas do desejo. São Paulo:

Brasiliense, I987, p. I73-I90. p. I57-I64, p. I78-I79. Seleciono esse trecho, mas devo esclarecer que não são todos os agenciamentos que implicam grupos sujeito... Os grupos assujeitados o são justamente pelo caráter mortífero dos agenciamentos de que participam.

7 STENGERS, Isabelle, I997, op. cit., p. 74, nota 2. As ideias de processualidade ontológica e criacionismo axiológico são de Guattari, para quem os valores entre os aborígenes australianos e os ameríndios teriam uma textura ontológica. Sobre a inspiradora perspectiva ontológica criacionista que desenvolvia no ano de sua morte, ver essa entrevista realizada em I992: GUATTARI, Félix; UNO, Kuniich. Chaosmose, vers une nouvelle sensibilité. In: GUATTARI, Félix. Qu'est-ce que l'écosophie? Textes présentés par Stéphane Nadaud. Lignes/Imec, 20I3, p. 83-98.

8 DELEUZE, Gilles; GUATTARI, Félix. Mil platôs - capitalismo e esquizofrenia. V. 2. Rio de Janeiro: Editora 34, I995. 
intermédio de um raizeiro caraíba que Taradjo, morador da aldeia Pakaya, chegou à União do Vegetal e sua equipe médica em uma cidade mato-grossense chamada Alta Floresta. Mareaji me descreveu o impressionante afluxo de pessoas provenientes de todo o Brasil e ressaltou antes de mais nada uma equipe de médicos-pajés supercompetentes por somarem à sua qualificação os poderes do vegetal, dotados de grandes recursos financeiros, boa vontade e grande interesse em assumir a responsabilidade médica pela saúde indígena, incluindo-se aí a construção de um hospital e coisas que tais.

Mahum, que vive na aldeia Paquiçamba e se tornou mais tarde o representante dos Yudjá na UDV em Cuiabá, me contou que partiu dele a sugestão de arranjar ayahuasca para os Yudjá tomarem na própria Terra Indígena. Era uma ocasião em que as pessoas estavam sendo muito afetadas por feitiçaria provocada por homens pertencentes aos povos que vivem rio acima. Naquele momento, Mahum presenciava um grupo de pessoas imaginando como seria bom se encontrassem a planta de poder usada antigamente, a árvore huririku, e propôs ao cacique e às demais pessoas que seria legal arrumar ayahuasca, e acabou-se chegando à União do Vegetal. Quando todo mundo se reuniu para beber na aldeia Pakaya, foi uma choradeira pelo reencontro com os seus mais velhos que já tinham morrido. Houve - me disse a esposa de Mahum - uma saudação lacrimosa entre os Yudjá e as almas dos seus parentes mortos. Assim as pessoas conheceram a potência do mariri.

Não me encontrei durante minha pesquisa com nenhum membro da UDV. Mas enquanto eu estava em Tubatuba uma equipe de 2I pessoas (segundo me contou Mareaji) esteve durante vários dias na aldeia Aribaru no começo de outubro do ano passado (20I6), acompanhados de um grande pajé caraíba norte-americano que ali estava para fazer uma reunião sobre a Terra. Em Aribaru se fez uma festa para recebê-los, sem cauim, segundo os rumores ouvidos em Tubatuba - Bebida alcóolica não pode! Por meio da divulgação desse evento na internet, tomei conhecimento da existência da ONG Associação Novo Encanto de Desenvolvimento Ecológico, em cuja página se afirma que a ligação com os Yudjá começou em 2oII, por iniciativa de voluntários do Departamento Médico Científico do Centro Espírita Beneficente União do Vegetal, e prossegue com ações do Departamento de Plantio e Meio Ambiente da UDV. A página e o vídeo de divulgação do evento, definido como "vivência intercultural", nada dizem sobre ayahuasca, contudo.

O encontro com a UDV, sem dúvida, colocou de um modo renovado e intenso entre o pessoal de Tubatuba uma questão crucial, a da boa distância, isto é, de como garantir uma política de boa vizinhança com os Brancos. Pois é claro que a ayahuasca trouxe para os Yudjá inspirações e ensinamentos destoantes daqueles de seus mestres caraíbas - o que provocou alguns "estranhamentos", "dificuldades de entendimento" (como me disseram) da parte do pessoal da UDV, e se a política adotada pelos Yudjá não foi de enfrentamento - quer dizer, de discussão - entre si, rolaram contudo intervenções muito eficientes na construção e transformação das relações com os udevistas. Em território Yudjá era preciso agir como Yudjá! 
- No começo disseram que não ia atrapalhar na cultura, mas depois foram aparecendo algumas coisas que foram mexendo com nossa raiz.

- Se a gente nasceu assim, por que a gente vai seguir outra linhagem?

As pessoas apontaram a experiência de Yabaiwa como precipitadora de uma reviravolta e da emergência das práticas rituais que pude presenciar.

Yabaiwa me contou que o que se sente, se vê e se pensa varia enormemente conforme o lugar onde se toma a ayahuasca, devido ao fato de serem diferentes os donos dos diferentes lugares. Quando lhe sucedeu tomar em Tubatuba, sentiu algo muito diferente do que vivenciara no centro da UDV, onde viu mais o mundo do Branco, ou melhor,

- Não era só o mundo do Branco que tinha ali: este ficava de um lado, mas ao olhar para o outro lado eu entrava num mundo indígena. Então percebi que não era só um mundo que estava ali. Quando tomei aqui na aldeia, senti diferente. As coisas que vinham em minha cabeça eram Yudjá mesmo... O chá, eles que tinham preparado, mas era no mundo Yudjá que eu entrava.

Desde o início disse Yabaiwa sentir-se um pouco à distância, pensativo e observando as pessoas Yudjá agirem segundo o que o pessoal da UDV definira para elas, até que um dia comentou com seu pai:

- Será que estou entendendo diferente? O que estou vendo é diferente do que fala a UDV. Estou me sentindo diferente!

Mas Yabaiwa não quis contar ao pai, deixando para quando surgisse a hora certa de falar com as pessoas.

- De repente tudo isso mudou dentro de mim. Nossa! - pensei. Se é assim tenho que cantar, vou cantar em minha língua, todo mundo vai sentir, vai saber o que o canto está dizendo... Comecei a cantar nossos cantos Yudjá...

Foi esse um momento crucial na história do encontro com a ayahuasca e os udevistas: pessoas rememoraram para mim com emoção a irrupção do canto na noite, frisando a potenciação da embriaguez provocada pela canção. De acordo com Yabaiwa, as canções em seu próprio idioma têm um poder de afetar as pessoas Yudjá de uma maneira que as "chamadas" em português não têm:

- Muitos não entendiam as chamadas. Sentiam a força, a luz também. Enxergavam, mas não acessavam... Porque cada canto é cada figura, cada canto tem seu poder, sua força. Entendi que o canto é uma arte... Quando você canta lá você vê cada figura, é um desenho! É uma coisa colorida, você vai colorindo com o canto! Quando senti isso, achei muito interessante. Então é assim ? - entendi! 
E as sessões passaram a fazer coexistirem as chamadas udevistas e as canções recebidas por Yabaiwa, e outros homens jovens foram também recebendo canções, em Yudjá como em português. Como me disse Areayaku, esses cantos induzem alegria entre as pessoas Yudjá. Não demorou para que um novo encontro, em meados de 20I4, dessa vez com pajés Ashaninca do rio Amônia, impulsionasse a pajelança entre os Yudjá, contribuindo com novos cantos na língua desse povo e talvez também com modulações da gestualidade introduzida pela UDV. Algumas pessoas também foram presenteadas por seus parceiros oníricos ou visionários com nomes próprios e imagens de cocares que puderam copiar, cocares que operam como veículos de poderes xamânicos e que também convém usar, como disse Tawaiku, em eventos políticos importantes do ativismo indígena.

Yabaiwa me contou que sua felicidade não impedia certa tristeza por não ter tido o seu finado avô a chance de experimentar ayahuasca. Yabaiwa desejava tanto que isso tivesse acontecido. Também eu tinha sido testemunha da vontade de virar pajé que o seu avô dizia ter, e de seu insucesso...?

- Meu avô, nas histórias que meu avô me contava eu vi tudo que estou sentindo hoje... É por isso que tenho que acreditar: Não é à toa que essas histórias ficaram para ser contadas!

Foi de Yabaiwa também a inspiração de reunir os companheiros que estavam recebendo canções para ir dizer ao cacique que os mais velhos tinham de ensinar-lhes os cantos de pajé antigos. Argumentaram que os cantos que andavam recebendo tinham a ver com o mundo atual, mas o mundo que já tinha passado estava assistindo os Yudjá, estava olhando para as pessoas, e não deviam esquecê-lo. Aquele mundo simplesmente estava parado, interrompido, por falta de alguém para trazê-lo de volta.

- Não acabou. Está parado mas está vivo! Está perto de você, só precisa prestar atenção que vai trazer eles de volta. Se chamar, eles vêm.

Em suas conversas comigo, mais de uma vez Yabaiwa afirmou que é preciso esperar a hora certa de falar. Como os demais jovens, ele nunca tinha visto pajelança Yudjá ou ouvido os cantos de pajé porque se dizia que é desrespeitoso e perigoso cantá-los fora do momento apropriado. Os mais velhos aceitaram suas exigências e acordaram com os jovens a realização periódica de um ritual mais íntimo ou seleto dedicado estritamente à transmissão dos conhecimentos xamanísticos de que eles têm memória.

- O passado não está no passado. Você se lembra, vem no presente.

Yabaiwa me disse ter finalmente entendido a razão de seu avô não ter conhecido a ayahuasca, e de terem sido os jovens que em todas as aldeias Yudjá assumiram o

9 LIMA, Tânia Stolze. Um peixe olhou para mim - o povo Yudjá e a perspectiva. Rio de Janeiro: NuTI/ISA; São Paulo: Unesp, 2005. 
cuidado com o vegetal. É que o vegetal veio para mudar o mundo, fazer um mundo novo. Daí essa virada para o contrário na política geracional e na ética do cuidado ${ }^{\text {To }}$.

- Os mais velhos, os que cuidavam, hoje passaram a ser como jovens, estão acompanhando os jovens, não é mais o contrário. Foi quando entendi isso... Se é assim, então nós mesmos vamos nos responsabilizar.

(Decidiu, com isso, mudar o rumo de sua vida e abandonou os estudos na Faculdade Intercultural Indígena, na Universidade do Estado de Mato Grosso - Unemat.)

\section{A ayahuasca encontra os Yudjá}

Nos últimos anos, Tarinu se tornou um narrador tão prestigiado que pude vê-lo capturar a atenção das pessoas mesmo durante uma cauinagem. Yabaiwa diz considerá-lo um historiador, para ele uma das atividades mais importantes, pois um narrador atua como uma raiz de pessoas, e dessa raiz depende o fortalecimento, o poder, isto é, o conhecimento das origens, mas também, sem dúvida, esta notável compreensão:

- O passado não está no passado.

Já volto a Tarinu. Acredito que a qualquer ouvido de amazonista, como é o meu caso, essa ideia de Yabaiwa evocaria o célebre paradoxo da narrativa mítica, assinalado por Lévi-Strauss - um paradoxo em razão da ambição da narrativa mítica de manter com o presente ao mesmo tempo uma relação disjuntiva e uma relação conjuntiva ${ }^{\text {II }}$.

"Não temos que procurar, afirmou William James, de onde provém a ideia, mas aonde ela conduz"ז2. O passado que não passou foi indicado por Yabaiwa como a única saída que nos permitiria ter um futuro, e como um "olhar grande" - o que, segundo ele me disse estar sendo levado a supor, falta aos Brancos. É por falta desse passado "irrelativo" que o nosso futuro comum está sob ameaça. Essa ideia de um passado que não passou deslanchou entre os Yudjá uma "pesquisa", um "estudo", uma "reflexão", uma atividade de pensamento exploratório a propósito de como podem vir a ter um futuro os Yudjá (mas não apenas eles).

Além de nos convidar a pensar um tempo em estado puro, se assim posso me exprimir, o tempo que remonta a sua indivisão em categorias temporais relativas, parece-me que a ideia de Yabaiwa merece ser entendida na acepção que o termo tem na pragmática jamesiana. Ou seja - e recorro novamente a um interessante

Io Dizem-se jovens todas as pessoas que assumiram o caminho de virar pajé com quem conversei. Elas se encontram em sua maioria na faixa dos 30, algumas na faixa dos 20 anos.

II LÉVI-STRAUSS, Claude. O pensamento selvagem. São Paulo: Cia. Editora Nacional, I976, p. 27 I.

I2 LAPOUJADE, David. William James. Empirisme et pragmatisme. Paris: Les Empêcheurs de penser en rond/ Le Seuil, 2007, p. 59-60 (tradução minha). 
estudo de Lapoujade -, não se trata de abordar as ideias enquanto forma, mas enquanto função, não se trata de indagar o que é a ideia, mas o que ela faz; importa menos que ela seja pensada do que faça pensar. Seria esta a "sua propriedade essencial: produzir efeitos no pensamento e no corpo. A ideia age; e ela não age sem fazer agir. [...] As ideias são condutoras"13.

Volto agora a Tarinu, por cujo intermédio também podemos perceber o sentido da ideia de pragmática especulativa, que me é inspirada por uma proposta de Debaise e Stengers, da qual tomo a sugestão de que o sentido de uma "operação especulativa" é justamente "suscitar possíveis" I4. Junto a mim, Tarinu atuou com um narrador dedicado ao exercício de recuperação da história do mariri. Ele era sensível à indagação que mobilizava os Yudjá por ocasião da chegada da ayahuasca (e os mobiliza ainda). As pessoas queriam saber como era possível que os brancos a tivessem trazido para elas. E se diziam que a ayahuasca os procurara tanto que conseguiu encontrá-los - finalmente!

Foi depois de muita caminhada, depois de uma infinidade de tempo à procura dos Yudjá, de numerosas paradas entre os diversos povos indígenas encontrados ao longo de sua busca, que mariri alcançou o seu destino. Embora isso me lembrasse a longa procura do rio Xingu pela humanidade após o dilúvio, no tempo da criação, me era indecidível se o relato de Tarinu era ou não era um estado germinal de um mito do cipó, ou somente uma expressão de afeto e de sedução, um relato especulativo de como se teria dado esse encontro do ponto de vista do cipó, isto é, como uma descoberta recíproca. Mariri já não tem mais motivo para seguir sua caminhada, ele chegou e se fixou. Os Yudjá pertencem a mariri, e este aos Yudjá.

Estar sob o efeito da ayahuasca não é entre os Yudjá um estado de passividade mental - foi o que praticamente eu disse a eles para justificar que não tinha conseguido praticar o que tinham me ensinado. É preciso manter o pensamento ativo, em um diálogo inicial consigo mesmo, antecipando o que se deseja ver e ali concentrando o pensamento. As forças transformativas metamórficas ativadas pelo ritual fazem as ideias aparecerem como imagens visuais, como impressões sensório-motoras. Em outras palavras, convém induzir a ayahuasca a te mostrar o que você deseja ver, assim como é preciso conjurar as imagens que te fazem sentir-se mal ou te amedrontam. As imagens são comunicativas, elas interagem com você. E mantendo o pensamento ativo você pode contribuir para o seu desdobramento - pois elas têm um modo de desenvolvimento, como me disse Yabaiwa.

Foi assim a própria ayahuasca que inspirou a Tarinu a recuperação de sua história. O criador da humanidade se comunicou com Tarinu, em resposta ao seu apelo, contando-lhe a respeito de mariri, um remédio que a humanidade abandonou no alto da montanha para onde tinha sido levada pelo criador por ocasião do dilúvio que precedeu a diversificação da humanidade. Quando as águas diluvianas baixaram e os Yudjá seguiram com o criador em busca do canal do rio Xingu, o remédio, por esquecimento, foi largado no alto da montanha, encontrado depois pelos Yudjá que

I3 Ibidem (tradução minha).

I4 DEBAISE, Didier; STENGERS, Isabelle. L'insistance des possibles: pour un pragmatisme spéculatif. Multitudes, n. 65, 20I6, p. 82-89. Disponível em: <cairn.info/revue-multitudes-20I6-4-page-82.html〉. Acesso em: I2 dez. 2017. 
se deixaram ficar para trás e não realizaram o percurso até o rio Xingu, terminando por se transformar em outros povos indígenas. Em sua busca dos Yudjá atuais, mariri assim perfez o caminho da humanidade antiga até o Xingu.

Pertencemos à ayahuasca "desde o início da vida”, para usar a expressão de Tawaiku. Vejo nesses atos de pensamento dedicados à retomada da ayahuasca algo como uma poética engenhosa, criadora da duplicidade que acredito ser inerente ao acontecimento entre os Yudjá ${ }^{15}$. Um pouco, então, para explicitar e resumir o argumento subjacente desse relato. A sequência de ações e interações envolvendo uma equipe de médicos da UDV na chegada da ayahuasca entre os Yudjá em Tubatuba e a experimentação ritual e onírica que isso deslanchou, isto é, a face maquínica do agenciamento, se ela tem sua formalização independente da face expressiva, ambas são inseparáveis, no sentido de que os enunciados, motivados pelas falas antigas, antecipam, preparam ou promovem remanejamentos do agenciamento, dando margem à operação de retomada do passado, de reocupação dos mundos espirituais e aos processos de ressingularização da pajelança entre os Yudjá. Não há, com efeito, como deixar de lado aqui o comentário de Stengers sobre a operação do reclaiming que ela encontrou por intermédio de Starhawk:

Reclaiming significa recuperar aquilo de que estivemos separados, mas não no sentido de que podemos tê-lo de volta. Recuperar significa recuperar-se da própria separação, regenerar o que essa separação envenenou. Ficam assim irredutivelmente ligadas a necessidade de lutar e a necessidade de curar, para evitar a semelhança com aqueles contra quem temos de lutar ${ }^{16}$.

\section{OS PAJÉS APRENDIZES EM AÇÃo}

Não sei se o pessoal da UDV veria ou não com bons olhos a emergência de práticas de cura em Tubatuba.

Segundo me contou Yabaiwa, ele foi inspirado a pôr em ação certas condutas dos pajés antigos, especialmente o uso da resina perfumada kadikka e de buquês das folhas unãha, e foi ensinado que para se efetuar uma cura era preciso cumprir a indicação feita, segundo as ocasiões, pelos espíritos. As curas assim passam, para os aprendizes, por um exercício de experimentação variável segundo as circunstâncias, e deles exige autoconfiança.

Tawaiku me contou com vivacidade como foi que em Tubatuba se assumiu a atividade de cura. Tahu, um homem velhíssimo, tinha sido levado para Tubatuba entre a vida e a morte e nem era mais capaz de se levantar da rede. Em uma ocasião em que se tomava ayahuasca, Yabaiwa cantava para fazer virem os espíritos, junto

I5 LIMA, Tânia Stolze. O dois e seu múltiplo: reflexões sobre o perspectivismo em uma cosmologia Tupi. Mana, Rio de Janeiro, n. 2, v. 2, I996, p. 2I-47. p. 39.

I6 STENGERS, Isabelle. Reclaiming animism. E-flux journal\#36, 20I2. Disponível em: <www.e-flux.com/journal/ reclaiming-animism>. Acesso em: I2 dez. 2017 (tradução minha). 
a um grupo de pessoas que depois veio a formar a equipe de pajés e auxiliares que hoje atua em Tubatuba. Chegaram os espíritos das músicas, e Yabaiwa pediu que as pessoas se levantassem e cantassem para afugentar os espíritos que estavam pondo em risco a vida de Tahu. Me contando, Tawaiku chega a rir de sua completa impossibilidade de levantar-se da cadeira, manter-se erguido e andar. Mas mesmo sob o efeito de uma tal força ainda se recebe orientação.

\section{- Aguenta aí ! Você tem que cantar!}

Os cantos tornaram clara a visão, e Tawaiku, mesmo de olhos fechados, via o círculo de seus companheiros ao redor de Tahu. Mas os companheiros tinham ficado muito diferentes. Ele via outros que não os companheiros, e quando Tawaiku olhou para si próprio, ele era diferente também, pois usava um imenso cocar de penas de harpia que lhe tirava todo o equilíbrio característico de quem se sente com os pés firmes no chão. A indicação de Yabaiwa era que deviam cantar e sacudir os buquês de folhas unaha para afugentar os maus espíritos e fazer-lhes uma barreira. Era um combate entre esses espíritos e aqueles cuja aparência revestia a dos companheiros. E com a força de um vento, os adversários quase provocaram a queda de Tawaiku quando chegou a sua vez de fazer o benzimento em Tahu. Não posso dizer quantas vezes as pessoas se reuniram para lutar pela vida de Tahu, mas, depois que conseguiram encontrar e devolver-lhe a alma, e Tahu pôde voltar para sua aldeia, resolveu-se formalizar uma equipe de pajés aprendizes para curar juntos.

- As doenças, a gente vê aqui como doenças; espiritualmente, são espíritos, as doenças [...]. Tem muitos espíritos de olho na gente! No sonho, a gente luta muito.

Tawaiku me disse também que nunca teve o desejo de ser chamado de pajé. É como cientista natural que gostaria de ser reconhecido. A ayahuasca, como me afirmou Yabaiwa, é uma ciência da natureza, e é boa para se investigar os povos indígenas e as nações em geral. Mais do que isso, até:

- A gente não pode mais separar o Branco e o Índio. Claro que cada um nasceu com um espírito, mas estamos vivendo em um mundo só. Assim que eu sinto, fico analisando isso, é como uma pesquisa...

Além da interação com inkundama - termo que eu entendo como uma designação dos invisíveis, ou espíritos num sentido genérico -, dá-se na pajelança de ayahuasca, como na prática onírica por ela estimulada, a criação de relações com pessoas de outros povos indígenas, e reencontros com pessoas que se pôde conhecer durante cursos, reuniões ou eventos do movimento indígena. Areayaku ressaltou que é muito bom tomar ayahuasca no domingo, porque isso está acontecendo em muitas aldeias Brasil afora e as pessoas podem se conectar.

O que se oferece quando se toma ayahuasca é uma infinidade de caminhos, e entroncamentos de caminhos, com os seus desvios, seus obstáculos e becos sem saída. De acordo com Yabaiwa, os caminhos formam uma grande rede cujas pontas 
se encontram no topo onde se acha a força maior. Tawaiku entende que essa rede descreve como o mundo (da ayahuasca) funciona. Uma mulher, Txiünahã, pegou o rumo da chuva. Kudaki, também uma mulher, pegou o rumo de Selã’ã (ela parou de percorrê-lo já tem um tempo, e nunca me disse uma palavra a esse respeito). Mahum, que vive na aldeia Paquiçamba, e Taradjo, da aldeia Aribaru, pegaram o caminho dos espíritos dos mortos. Yabaiwa e talvez também Karin pegaram o caminho do céu e de Kumahari. Yabaiwa também frequenta o caminho dos Ashaninka e de outros povos. Areayaku tem a medicina caraíba como um de seus caminhos e já transitou no caminho dos Tikuna. Tawaiku está no caminho das plantas e também transita no caminho dos Incas. Ignoro os caminhos de Aduala, mas pelo que ela me disse suponho que pelo menos algum deles tenha a ver com o português oral e escrito.

Talvez os mitos também sejam ou tenham seus rumos. Várias pessoas relembraram para mim um ritual que tomou um mito como uma engrenagem sua. Tarinu conduziu a narrativa da criação e algumas pessoas puderam testemunhar "o início da vida”, testemunhar “como o mundo foi mudando...” "É tão interessante...”

- Nem dá para descrever a emoção... Estamos no futuro do passado, esse nosso presente. [...] Esse é o principal caminho: deixar as pessoas se sentirem como ser humano - é esse o estudo!

Assim se exprimiu Tawaiku, prestes a me sugerir que a prática da ayahuasca e a experiência do aiôn que os Yudjá, ao que tudo indica, nela redescobriram teriam muito de uma viagem filosófica, viagem que só conduzisse os Yudjá para as terras mais distantes levando-os para um encontro consigo mesmos.

Mas, quando cheguei em Tubatuba em julho do ano passado, não estava havendo pajelança de ayahuasca em respeito ao luto de Yabaiwa, que estava muito triste ainda pela morte de um filho seu no mês de abril. Havia a expectativa de que a qualquer momento ele desse o sinal de que as pessoas podiam fazer suas pinturas corporais, como é característico da cerimônia de suspensão do luto. Mas isso não aconteceu. Depois dessa cerimônia, me diziam, eu teria a chance de participar de uma festa no Kubepa, a casa da ayahuasca - o que tampouco aconteceu. Essa festa não se resumia contudo a um ritual de ayahuasca. Era antes uma cauinagem com os invisíveis. Conforme tinha me contado Tarinu, o espírito de mariri, ou o mariri enquanto espírito, foi quem pediu em sonho para mandar fazer uma cauinagem para ele. Não sei que considerações o pessoal da UDV teria a fazer a propósito dessa festa, uma vez que o que se presume é que esse pessoal não admite bebida alcoólica e considera como tal o cauim Yudjá.

“[A] realidade e o tempo do agenciamento 'prendem-se' ao acontecimento" afirmou Guattari ${ }^{17}$. Foi, com efeito, a primeira tempestade da estação no dia I5 de setembro que pôs o agenciamento Yudjá em movimento. As pessoas acusam que nos últimos anos têm caído tempestades assustadoras. Um homem jovem morreu fulminado no Natal de 20I2. Uma mulher já foi atingida três vezes. Dois outros jovens foram atingidos também. E no fim da tarde de 15 de setembro o traumatismo

I7 GUATTARI, Félix. Falação em torno de velhas estruturas e novos sistemas, op. cit., p. I6I. 
provocado por esses acidentes afetou mais uma vez os três sobreviventes e suas famílias. Perda de consciência, embriaguez, e, na casa de um deles, Tupãw, podia-se até mesmo sentir de novo o odor da descarga elétrica. Os pajés foram assistir as vítimas e lutar para restabelecê-las com ayahuasca. Foi essa tempestade que precipitou o ritual de ayahuasca que se realizou dois dias depois. Previsto para acontecer no meio do terreiro central da aldeia, uma nova tempestade começou a lançar os seus sinais antes das sete da noite, mas por volta das oito, quando apareci, as pessoas já estavam formando um círculo ao redor de uma pequena mesa que fazia as vezes de altar. Pareceu-me que ainda ia começar, e só entendi muito depois que o ritual já estava em curso e consistia em um exercício de conexão do pensamento com as forças atmosféricas. Ventos, relâmpagos e logo depois muita água nos expulsaram para o interior de uma casa, onde por bem mais de uma hora se manteve a guarda e se quebrava o silêncio com sopros e gestos de mandar a chuva embora, para montante. Chuva controlada, era hora de fazer a conexão do pensamento com a ayahuasca e convocar suas forças. Tawaiku me contou no dia seguinte que demorou a sentir o efeito e, enquanto pedia para vir a força e pensava em tomar outra dose, Yabaiwa começou a cantar e aí a força veio tão forte que Tawaiku teve de ficar se dizendo que era preciso resistir. Ele estava ao lado de Aduala, uma mulher que também é aprendiz de pajé, e percebeu que também foi difícil para ela se erguer no momento em que Yabaiwa deu o sinal para começarem os benzimentos das vítimas de raio e das pessoas que andavam doentes, ou estavam passando mal por ação de algum espírito vindo com a ayahuasca. É preciso coragem para enfrentar, as forças que causam as doenças lutam contra as que se aliam ao pajé. É preciso apostar. Precisamos também ser fortes, me disse Areyaku, porque as almas dos mortos vêm e nos causam choro. Fortes para não chorar.

Suponho que uns quatro pajés estiveram curando naquela noite. Desejei poder ver sua atuação, mas eu desejava mais ainda ver as imagens, as figuras engrenadas umas nas outras. Sacudindo grandes buquês de folhas de unaha os pajés aprendizes produziam grandes efeitos sonoros. Como um prolongamento metamórfico da sonoridade farfalhante e ritmo acelerado desses buquês, surgia para mim linda música produzida pelo bater das asas de pássaros pesados, de grande envergadura, pássaros que mal se equilibravam a uma distância aproximada de uns dois metros do solo. O volume, o peso, a envergadura, além da música alucinante dos pássaros invisíveis.

Sempre vem muito gavião-real - me disseram no dia seguinte. Muita onça e muita cobra também.

Ao fazer a chuva entrar como uma engrenagem do ritual daquela noite, Yabaiwa reduziu os cantos a um número mínimo, pois, se era preciso tornar presentes os poderes xamanísticos, era igualmente preciso conter a comunicação entre o céu e a terra. Os pajés tampouco usaram maracás porque visavam menos convocar que conjurar espíritos. Houve, ao fim do ritual, uma longa fala de Mahum, o representante dos Yudjá junto à UDV de Cuiabá, sobre uma viagem que pessoas da UDV programavam para o começo de outubro entre os Yudjá da aldeia Aribaru, durante a qual haveria um preparo de ayahuasca e a declaração das regras, e dizendo 
que os udevistas solicitavam uma permissão para visitar Tubatuba no dia I2 de outubro - visita que não chegou a ocorrer.

Os Yudjá insistiram muito que a embriaguez provocada pela ayahuasca também é provocada pela música que se canta ou toca durante o ritual, bem como pela chegada dos espíritos. Desse modo, pessoas que não tinham tomado ayahuasca também ficaram bêbadas e muitas tiveram uma noite de sonhos muito ricos. Paxiku me contou que isso tem muito a ver com a conexão entre todas as pessoas de Tubatuba efetuada pelo mariri, a qual pode ser visualizada no ritual: as pessoas se acham conectadas umas às outras pelos tornozelos com longos fios do cipó mariri.

Duas semanas mais tarde foi a minha pesquisa que foi arrastada para um pequeno ritual de pajelança. Eu ansiava por uma conversa com Karin, e ele quis puxar a minha pesquisa para a cura que ia fazer em sua avó, doente desde uma semana, quando sofreu um desmaio e convulsões. Ela vinha sendo tratada com ayahuasca diariamente, e também por pajelança de tabaco. Nessa noite éramos apenas a doente, seu marido (que é o cacique), Karin e eu. A sequência ritual foi: Karin falou para eu ouvir (em português) sobre a transformação da vida coletiva em Tubatuba, cantou para convocar os espíritos, extraiu doenças do corpo da avó, narrou em Yudjá a história de mariri e chacrona para eu aprofundar o conhecimento, e fez comentários sobre os cantos; ao fim, pude fazer perguntas e obter respostas, declarar minha alegria e apresentar minhas congratulações.

Karin cantou em yudjá, ashaninca e português. Interessou-me particularmente a execução de dois cantos de pajé antigos: um deles evocava a onça muito claramente pelo trabalho da voz e da respiração, contudo não pelas palavras. Mas forte mesmo por sua ação sobre mim foi a súplica cantada para convocar a divindade Kumahari. Como podia uma frase cantada, um trabalho de voz serem tão extraordinariamente inspirados? Quando o pajé se calou, o cacique fez uma breve e quase sussurrada intervenção trocando algumas palavras, mas com quem, com Karin? com a divindade?

Além de uma impressionante atuação na arte do sopro, também capturou minha atenção o que eu chamaria de cura dançada. Em pé, o movimento e os gestos de braços e mãos que acompanhavam um canto evocavam muito a harpia, batendo asas, as garras à mostra, e a doença quase como uma presa da ave durante o voo.

Quando a pajelança se abriu para minha pesquisa outra vez pude indagar um pouco a respeito da sutil passagem de Kumahari por minha pesquisa. O cacique e sua esposa haviam me falado longamente em I989 sobre essa divindade celeste junto a quem os guerreiros antigos foram viver após a morte... São eles que viram gavião-real para circular aqui na terra, e que comparecem aos rituais de ayahuasca. Acho que nunca encontrei na literatura sobre os povos da Amazônia referência a uma divindade tão temida como o Kumahari dos Yudjá, exceto talvez o Tupã dos antigos Tupi da costa, retratado nas crônicas seiscentistas. Uma divindade da guerra, canibal, apontada no passado como realmente perigosa para os Yudjá, e assunto cercado de silêncio ${ }^{18}$.

A Festa no Kubepa de que tinham me falado e torciam para que eu pudesse 
participar, apontada como uma cauinagem dedicada ao mariri, agora, na pajelança que Karin acabava de fazer era definida pelo cacique como cauinagem oferecida a Kumahari: trata-se de uma festa que começa com uma sessão de ayahuasca e se desdobra em uma cauinagem muito solene, em que os Yudjá bebem, cantam e dançam em meio às divindades.

Retornarei mais adiante à pajelança de Karin, para aqui acrescentar dois episódios que contudo só conheço por meio de rumores. Como se não dependesse de mim vencer o entorpecimento que provocaram nesta etnógrafa, não me sucedeu explorar a pista aberta por eles. Kumahari exigiu dos Yudjá um pagamento da ayahuasca. Exigiu de Yabaiwa uma esposa, sob a ameaça de raptá-lo e prendê-lo no mundo celeste. Uma exigência dessa natureza, segundo me contava no passado o finado avô de Yabaiwa, era uma conduta comum a Kumahari, mas não se inferia disso que as esposas humanas dessa divindade, as quais davam nascimento a crianças que eram pajés de nascença, também eram esposas de pajés humanos ${ }^{19}$. É isso, porém, o que se tem dito que se passou com Yabaiwa. Ele contraiu, com efeito, um segundo casamento, e se diz de sua segunda esposa que ela seria uma esposa de Kumahari. E de seu filho morto em abril, que era uma criança de espírito. Puxei o assunto sobre essa condição da criança com Tarinu, por ser ele o avô.

- Pois é! é o que parece... o pessoal tá dizendo...

Não teria mesmo talvez valido a pena a pretensão de explorar o assunto, como se o rumor ele mesmo fosse ineficiente para participar da composição da face expressiva do agenciamento. Como se - e isso é mais importante ainda - esses elementos pragmáticos e especulativos, tais como "parece que...", "talvez sim...", "se diz que...", "é preciso acreditar...", não fossem ferramentas cruciais para lidar com "a insistência dos possíveis" e para pôr em movimento a pragmática especulativa agora direcionada, até onde posso presumir, para a apreensão do ponto de vista de Kumahari sobre tudo isso.

Comenta-se que o pessoal da UDV desaprovou por ocasião de certo ritual as segundas núpcias de Yabaiwa, e que este, ao tomar a palavra, a sua fala, que não foi vertida para o português, teria esta tônica:

- Eu nasci assim e não posso ser diferente do que sou!.

Yabaiwa, que não julgou importante abordar o assunto comigo senão de maneira muito indireta, me contou o que disse a um amigo que trabalha desde algumas décadas na Terra Indígena do Xingu.

-“Se nós nascemos assim! Se para nós não é problema! Por que...?” Falei com ele: "Não quero ser dono de ninguém, não quero ser dono da União do Vegetal, não quero ser dono do Ashaninca, mas quero aprender o meu dono! Quero aprender o meu

I9 LIMA, Tânia Stolze. A parte do cauim - etnografia Juruna. Tese (Doutorado em Antropologia). 480f. PPGAS-Museu Nacional, Universidade Federal do Rio de Janeiro, I995. 
dono! Não quero mandar: Ah assim, aqui você não pode fazer, aqui faça isso! Não posso falar assim para um líder espiritual. Porque ele é um pesquisador espiritual. O que ele faz, ele sabe...”.

Foi a conversa que abriu a pajelança de Karin que despertou minha atenção para a conexão entre a pajelança e a liderança. Yabaiwa e Karin são os pivôs da escola de Tubatuba e da Associação Arikayu, têm formação universitária, participam ativamente de cursos variados, do trabalho de representação política e militância indígena. E são os pivôs da pajelança de ayahuasca em Tubatuba. Uma hipótese que me parece plausível é, portanto, a de que a tomada de consistência do agenciamento xamanístico dependeu de uma simbiose que se soube efetuar entre as posições de liderança e de pajé. Yabaiwa e Karin são ainda companheiros muito estimados e excelentes diplomatas que efetuam a mediação com o Instituto Socioambiental (ISA), as equipes médicas, a secretaria de educação e pessoas de outros povos indígenas. Chamou-me a atenção o empenho que demonstram em tornar sensível para todos, moradores da aldeia e estrangeiros, a importância de se prezar a posição do cacique, a hospitalidade e o respeito. $\mathrm{O}$ acontecimento que busquei talvez resida na efetuação dessa simbiose entre pajés e lideranças especializadas nas conexões com "os de fora", de modo a fazer a política indígena um dos modos de existência do xamanismo.

Karin discorreu sobre como a ayahuasca alterou profundamente a vida coletiva. Tubatuba antiga vivia sob o constante ataque de feiticeiros, e os jovens não estavam aí para nada; tudo era muito desarticulado, e a cachaça entrava direto na aldeia. É mais tranquilo, disse, enfrentar os desafios, como os cursos, as viagens, as reuniões políticas, os doentes - sem contar que os Yudjá se tornaram fortes para resistir aos evangélicos.

\section{-É planta mas é poderoso!}

Também se envolveu a Associação Arikayu com a educação dos estudantes, promovendo oficinas periódicas para a transmissão de conhecimentos, respeitando-se (quando é o caso) a divisão do trabalho por gênero, e se veio ainda a estimular interessantemente a pesquisa informal dos estudantes durante as cauinagens, porque estas também são "transmissão de conhecimento".

$E$ aos jovens que andaram se mostrando inquietos com vontade de saber o que era isso de "cultura Yudjá", Karin, sentindo-se mais forte, pôde passar a responder (acho que ao modo de uma provocação e de um encorajamento),

- A cultura é você! É você mesmo a cultura! Basta praticar! Pratiquem! É você!

A atividade ritual concernente à ayahuasca, em Tubatuba, é incrivelmente alomórfica, e o espaço não me permite abrir este relato para o importante ritual de afugentamento de feiticeiros que Karin, com o auxílio de Areayaku e Pinikaynahã, realizou dois dias mais tarde em benefício da cura de sua avó, nem para um pequeno ritual algumas semanas mais tarde em que se celebrou a finalização do trabalho de uma equipe de 
realizadores de um documentário, e também a minha despedida, em que Yabaiwa e Tawaiku tematizaram a diplomacia e a responsabilidade caracterizada como imensa de "entender o que está acontecendo lá fora" - ou seja: aqui! - de "acompanhar e analisar as propostas que vêm sendo construídas lá fora”, relacionadas quer aos povos indígenas quer aos destinos da vida na Terra.

Retrospectivamente, imagino que a animação, a alegria, o desejo que me chamaram tanto a atenção, e tanto me emocionaram, talvez tenham me inquietado e despertado a necessidade de entender o que está se passando em Tubatuba enquanto uma vida em processo de criação, em lugar de subordiná-la a formas culturais constituídas. Anular esses afetos seria mortal para o que pretendi apontar aqui, a saber, a criação de um problema aberto, e vital. Talvez o que pude fazer tenha sido traçar uma ponte, uma afinidade, entre a pista oferecida por essa importante arma indígena que se diz retomada ou reocupação e a pista da alegria na doutrina spinozista, que dela faz, como se sabe, um afeto político, e outras pistas que fui encontrando no percurso... Espero ter conseguido comunicar a vocês alguma coisa de um agenciamento cosmopolítico dedicado a tornar de novo habitáveis a aldeia Tubatuba, a Terra, o Cosmos e a Si mesmos. Afinal, para homenagear a resistência indígena, subtendida neste relato como "reapropriação processual da produção do mundo" 20 , fiquemos com este memorável grito de Ailton Krenak: "Não existiu uma criação do mundo e acabou! Todo instante, todo momento, o tempo todo é a criação do mundo"2.

SOBRE A AUTORA

TÂNIA STOLZE LIMA é etnóloga e professora aposentada do Departamento de Antropologia da Universidade Federal Fluminense (UFF).

E-mail: tania.stolze@gmail.com

\section{REFERÊNCIAS BIBLIOGRÁFICAS}

DEBAISE, Didier; STENGERS, Isabelle. L'insistance des possibles: pour un pragmatisme spéculatif. Multitudes, n. 65, 2016, p. 82-85. Disponível em: <cairn.info/revue-multitudes-20I6-4-page-82.html〉. Acesso em: I2 dez. 2017.

DELEUZE, Gilles; GUATTARI, Félix. Mil platôs - capitalismo e esquizofrenia. V. 2. Rio de Janeiro: Editora 34, I995.

20 GUATTARI, Félix; UNO, Kuniich, op. cit., p. 96.

2I KRENAK, Ailton. Antes, o mundo não existia. In: NOVAES, A. (Org.). Tempo e história. São Paulo: Companhia das Letras, I996, p. 20I-204. p. 203. 
DELEUZE, Gilles; PARNET, Claire. Diálogos. São Paulo: Escuta, I998.

GUATTARI, Félix. Falação em torno de velhas estruturas e novos sistemas. In: . Revolução molecular: pulsações políticas do desejo. São Paulo: Brasiliense, I987, p. I57-I64. . Micropolítica do fascismo. In: . Revolução molecular: pulsações políticas do desejo. São Paulo: Brasiliense, I987, p. I73-I90.

GUATTARI, Félix; UNO, Kuniich. Chaosmose, vers une nouvelle sensibilité. In: GUATTARI, Félix. Qu'est-ce que l'écosophie? Textes présentés par Stéphane Nadaud. Paris: Lignes/Imec, 20I3, p. 83-98.

KRENAK, Ailton. Antes, o mundo não existia. In: NOVAES, A. (Org.). Tempo e história. São Paulo: Companhia das Letras, I996, p. 20I-204.

LAPOUJADE, David. William James. Empirisme et pragmatisme. Paris: Les Empêcheurs de penser en rond/Le Seuil, 2007.

LÉVI-STRAUSS, Claude. O pensamento selvagem. São Paulo: Cia. Editora Nacional, I976.

LIMA, Tânia Stolze. A parte do cauim - etnografia Juruna. Tese (Doutorado em Antropologia). 480f. PPGASMuseu Nacional, Universidade Federal do Rio de Janeiro, I995.

. O dois e seu múltiplo: reflexões sobre o perspectivismo em uma cosmologia tupi. Mana, Rio de Janeiro, v. 2, n. 2, I996, p. 2I-47.

. Um peixe olhou para mim - o povo Yudjá e a perspectiva. Rio de Janeiro: NuTI/ISA; São Paulo: Editora Unesp, 2005.

STENGERS, Isabelle. Pour en finir avec la tolérance. In: . Cosmopolitiques. Tome 7. Paris: La Découverte/Les Empêcheurs de penser en rond, I997.

. Reclaiming animism. E-flux journal\#36, 20I2. Disponível em <www.e-flux.com/journal/reclaiming-animism >. Acesso em: I2 dez. 2017. 